\title{
Discussion and research on comprehensive evaluation of power supply reliability
}

\author{
Wen-Bo Wang ${ }^{1, \text { a }}$ and Zi-Ya Xing ${ }^{2, b}$ \\ ${ }^{1}$ State Grid Henan Electric Power Research Institute, Zhengzhou, China \\ ${ }^{2}$ State Grid Henan Electric Power Company, Zhengzhou, China \\ E-mail: ${ }^{a}$ wangwenbo623@163.com, ${ }^{b}$ xingziya@163.com
}

\begin{abstract}
Power supply reliability evaluation is an important link in the closed loop management of power supply reliability. It is of great significance to improve the professional management and the reliability of power supply reliability. Power supply reliability evaluation of power grid sustained supply capacity, grid technology and equipment level and management level of comprehensive and quantitative, which directly reflects the power industry of national economic power. It can meet the needs of the extent, reflecting the power system planning, design, construction, construction, facilities, equipment, production and operation, power supply service quality and management level. This paper combs the impact of the power supply reliability of key business and the establishment of comprehensive evaluation index system of power supply reliability. The identification of power distribution network is the problem and management of weak links. Effective measures need to be taken to improve power supply reliability of distribution network.
\end{abstract}

Keywords: Reliability; Comprehensive Evaluation; Analytic Hierarchy Process; Grey Relational Grade Analysis.

\section{Guidelines}

The distribution network is directly facing the user's link in the power system, and it is also the most direct impact on the quality of the power supply and the reliability of the power supply. The whole power system to the user's power supply capacity and reliability are reflected through the distribution network.

For power supply enterprises availability index. It is not only network each node voltage and branch active (reactive) loss, grid structure and electrical parameters the results of interaction, is the comprehensive embodiment of run production, planning and management, engineering, construction and other business and production departments work efficiency and working level [1].

Therefore, to carry out comprehensive evaluation of the reliability of power supply, and identification of weak links, to improve the reliability of distribution network and ensure power quality and improve the power industry production 
technology and management level, improve the economic benefit and social benefit to have very important significance.

\section{Analysis of Influencing Factors}

The statistical work on the reliability of equipment and systems began in 1983 in China, has accumulated a lot of experience. The reliability data of the power system equipment is released by the central electric reliability management center, which promotes the reliability management of the whole country [2-4]. Based on electric reliability center in recent years statistical data from grid level, planning and design, construction operations, production scheduling, operation and maintenance management and based on the six factors affect the reliability of the power supply were analyzed, as shown in the following figure 1 shows.

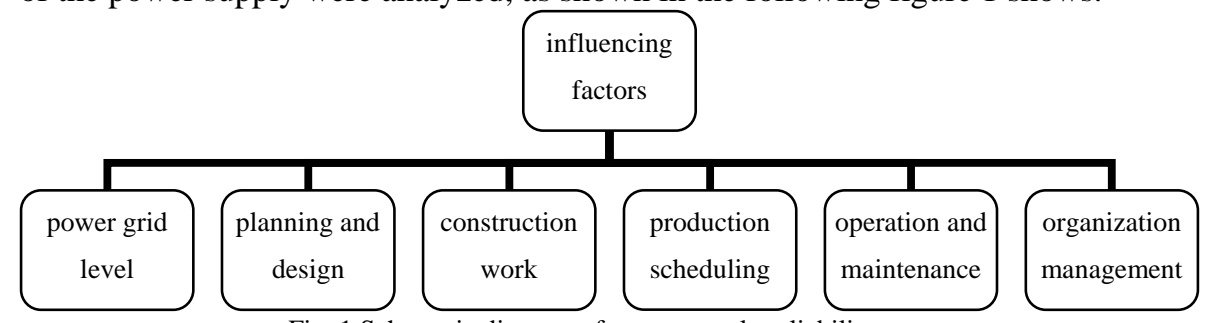

Fig. 1 Schematic diagram of power supply reliability

\section{Establishment of Comprehensive Evaluation Index System of Power Supply Reliability}

Power supply reliability comprehensive evaluation index system is the basis of distribution network reliability management and evaluation, through the establishment of the evaluation index system of power supply reliability, to the link index of quantitative form influence power supply reliability level of business guide the business sector and the business team clear himself in power supply reliability management problems, remove power supply reliability management in business dead, promote the power supply reliability management to lean of the direction of change[5-6].

\subsection{Principle of index establishment}

According to the purpose of statistical evaluation, select the appropriate statistical indicators, to establish a system to evaluate the main problems from different angles, different aspects of the evaluation index system. The establishment of evaluation index system, relevant theoretical basis, by qualitative analysis, quantitative analysis as a supplement, in addition should 
follow some basic principles, including: holistic principle, comparability principle, operational principle and guiding principle.

\subsection{Comprehensive evaluation index system of power supply reliability}

Based on the analysis of the influencing factors of the power supply reliability of distribution network, the evaluation index of each influencing factor is put forward according to the construction principle of the index, and the comprehensive evaluation index system of power supply reliability is presented in Table 1.

Tab. 1 comprehensive evaluation index system of power supply reliability

\begin{tabular}{|c|c|c|}
\hline \multirow{24}{*}{$\begin{array}{l}\text { power supply } \\
\text { reliability level }\end{array}$} & \multirow{3}{*}{ power grid level } & power grid level \\
\hline & & planning and design \\
\hline & & level of equipment \\
\hline & \multirow{5}{*}{ planning and design } & planning guide evaluation \\
\hline & & planning scheme evaluation \\
\hline & & load forecasting \\
\hline & & implementation of planning scheme \\
\hline & & investment plan implementation \\
\hline & \multirow{4}{*}{ construction work } & construction quality audit \\
\hline & & construction safety management \\
\hline & & construction outage time management \\
\hline & & construction schedule management \\
\hline & \multirow[b]{2}{*}{ production scheduling } & integrated power outage management \\
\hline & & distribution network to power supply \\
\hline & \multirow{7}{*}{$\begin{array}{l}\text { operation and } \\
\text { maintenance }\end{array}$} & equipment inspection \\
\hline & & equipment elimination \\
\hline & & trouble repair \\
\hline & & live working \\
\hline & & user side management \\
\hline & & maintenance management \\
\hline & & information system maintenance \\
\hline & \multirow{3}{*}{$\begin{array}{l}\text { organization } \\
\text { management }\end{array}$} & organization structure \\
\hline & & personnel professional level \\
\hline & & management system \\
\hline
\end{tabular}

\subsection{Index weight calculation}

The calculation of the index weight is the key to establish the comprehensive evaluation index system. This project uses analytic hierarchy process to calculate the weight of evaluation index[7]. The idea of this method is to first 
use gray correlation degree analysis method to calculate the degree of association between each evaluation index and reliability index, the association degree of size difference is transformed into the evaluation index for the reliability level influence degree of difference, then use the analytic hierarchy process analysis method to calculate the weight of each evaluation index.

In order to more accurately and reasonably measure the importance of the reliability index of each factor, drawing operations school level analysis method of constructing judgment matrix, with the square root method solving the feature vector, the application of consistency index to determine the weight of each factor.

\subsubsection{Judgment matrix}

Using analytic hierarchy process, the first need to establish a judgment matrix, as shown in the formula.

$$
A=\left[\begin{array}{cccc}
a_{11} & a_{12} & \ldots & a_{1 n} \\
a_{21} & a_{22} & \ldots & a_{2 n} \\
\ldots & \ldots & \ldots & \ldots \\
a_{n 1} & a_{n 2} & \ldots & a_{n n}
\end{array}\right]
$$

The importance of each element in the aij, its value can be based on data, expert opinion and experience, to discuss through repeated research and determine, in general the use of 1 9 to determine the degree of.

(a) Hierarchical ranking

Hierarchical ranking is the level of each of the elements with respect to the importance of the level of ranking, which requires the calculation of the weight of the matrix calculation [8]. The weights are calculated by the method, the root method, the power method, and so on, the most commonly used method is the root mean square method, the calculation steps are as follows [9]:

First, calculate the product of each line of the matrix Mi:

$$
M_{i}=\prod_{j=1}^{n} a_{i j} \quad i=1,2, \cdots, n
$$

Then, calculate the $\mathrm{n}$ of the Mi root mean square $\mathrm{Wi}$ :

$$
W_{\mathrm{i}}=M_{i}^{\frac{1}{n}}
$$

Normalization processing for Wi: 


$$
\omega_{\mathrm{i}}=\frac{W_{\mathrm{i}}}{\sum_{i=1}^{n} W_{\mathrm{i}}}
$$

$\omega=\left[\omega_{1}, \omega_{2}, \cdots, \omega_{n}\right]^{T}$ is the desired feature vector (weight).

(b) Consistency check

In order to reflect the relative importance of each factor, we need to check the consistency of the judgment matrix in order to check the consistency of thinking. The test index includes the consistency index $\mathrm{CI}$ and the random consistency ratio CR [10].

$$
\begin{gathered}
C I=\frac{\left(\lambda_{\max }-\mathrm{n}\right)}{n-1} \\
C R=\frac{C I}{R I}
\end{gathered}
$$

In formula (5), $\lambda_{\max }$ is the biggest characteristic root of the judgment matrix, $\mathrm{n}$ is the order of the judgment matrix. In formula (6), RI is random consistency index of different orders.

If $\mathrm{CR}<0.1$, it is considered that the judgment matrix has an acceptable consistency, otherwise the judgment matrix should be adjusted until the decision condition is satisfied.

\subsubsection{Weight calculation}

Based on the judgment matrix, the method of grey correlation degree analysis is used to calculate the weight of the six rings three.

\section{Evaluation method}

Refer to the State Electricity Regulatory Commission, the reliability evaluation of power supply enterprise implementation approach (Trial) "and the State Grid Corporation of the urban distribution network operation and power supply assessment guide", develop the scoring method of the indicators, realize the power supply reliability evaluation.

\section{Conclusion}

The factors that influence the reliability of power supply based on proposed the evaluation index of the influencing factors, a comprehensive evaluation index system of power supply reliability, contains a total of impact factors of 6,24 
secondary influence factors, and the realization of the comprehensive evaluation of the reliability of power supply.

This paper adopts analytic hierarchy process and determine the levels of influence factors and the weight of each evaluation index, so as to lay a foundation for the application of evaluation index system; proposed based on hierarchical linear model of the index grade method, combined with expert judgment, the piecewise linear model of the indicators.

\section{Reference}

1. State Grid Corporation of China. User power supply reliability management of power supply system [M]. Beijing: China Electric Power Press, 2012.

2. State Grid Corporation of China. Practical technology of power supply reliability management[M]. Beijing: China Electric Power Press, 2008.

3. State Grid Corporation of China. User power supply reliability management manual[M]. Beijing: China Electric Power Press, 2007.

4. State Grid Corporation of China. User power supply reliability of power supply system [M]. Beijing: China Electric Power Press, 2012.

5. State Grid Corporation of China. Power reliability management foundation [M]. Beijing: China Electric Power Press, 2012.

6. Bai Yichun. The reliability evaluation of power user electric power terminal based on [J].2007 (5).

7. Huang Jia, Liang Yong. To improve the reliability of distribution network measures [J], power grid construction, 2009 (6).

8. Huang Liangbiao. Evaluation and optimization of power supply reliability of distribution network [J]. Northeast electric power technology, 201435 (6).

9. Wu Yanan. Discussion on the main influence factors and management measures of power supply reliability of $10 \mathrm{kV}$ distribution network. Mechanical and electrical information, 2013 (33).

10. Liang Yongquan. Research and analysis of power supply reliability of $10 \mathrm{kV}$ distribution network. Construction engineering technology and design, 2014 (18). 